\title{
DIFFERENCES IN BEHAVIOUR, DOMINANCE AND SURVIVAL WITHIN A CLINE \\ AMATHES GLAREOSA ESP. (LEP.) AND ITS \\ MELANIC F. EDDA STAUD. IN SHETLAND
}

H. B. D. KETTLEWELL

Genetics Laboratory, Department of Zoology, University of Oxford

R. J. BERRY

Royal Free Hospital School of Medicine, London, W.C.1

C. J. CADBURY

Leighton Park School, Reading

(Formerly of the Genetics Laboratory, Department of Zoology, University of Oxford)

and

G. C. PHILLIPS

Unilever Research Laboratory (Colworth), Aberdeen

Received 10.iv.68

\section{INTRODUCTION}

ONE THIRD of the 62 resident species of moths in the Shetland Islands are represented partially or wholly by melanic forms (Kettlewell, 1961 $a$ ). One of these species is the Autumnal Rustic Amathes glareosa Esp., which has a distinct dark form, edda (Kettlewell and Berry, 1961, 1968). It is inherited as a dominant character. We spent four seasons in Shetland (1959-62) studying factors which could contribute to the maintenance of this dimorphism, in the confidence that such knowledge would throw light on the evolution and origins of the preadapted genotypes which have been involved in the spread of melanic forms in industrial areas during the last 150 years (Kettlewell, 1957, 1965). Our experimental work in 1959 and 1960 was reported by Kettlewell $(1961 b)$; this paper completes and summarises our work on A. glareosa. Altogether we caught over 30,000 individuals, of which 10,645 were marked and released, and 819 recaptured.

\section{BACKGROUND AND PROCEDURE}

Our visit to Shetland in 1959 was largely a reconnaissance during which we discovered that $f$. edda was not confined to Unst, the northernmost of the three large Shetland islands, as previously thought, and learned certain facts about the natural history of the species. In 1960 we determined the main features of the distribution of $f$. edda (Kettlewell and Berry, 1961), and undertook mark-release-recapture experiments at the two extremes of the range of $f$. edda, at Baltasound on Unst where the frequency of $f$. edda is 97 per cent., and Dunrossness in the south of the mainland (= main island) where $f$. edda is 3 per cent. of the $A$. glareosa population (fig. 1). These experiments involved the transport of $f$. typica from south to north, and $f$. edda from north to south by way of four different buses and two ferries each day. We made every effort to ensure that all moths released at a site were treated comparably. For example, all releases on any day were of moths caught on the same night, and individuals that were to be released at the site of capture were subjected 
to a car journey so that they would experience, as much as possible, similar treatment to those sent to another area for release. The techniques used and results have been described in full by one of us (Kettlewell, 1961b). We showed that there was a steady decline southwards in the frequency of $f$. edda, except in the area of Tingwall Valley, a region in the Central Mainland

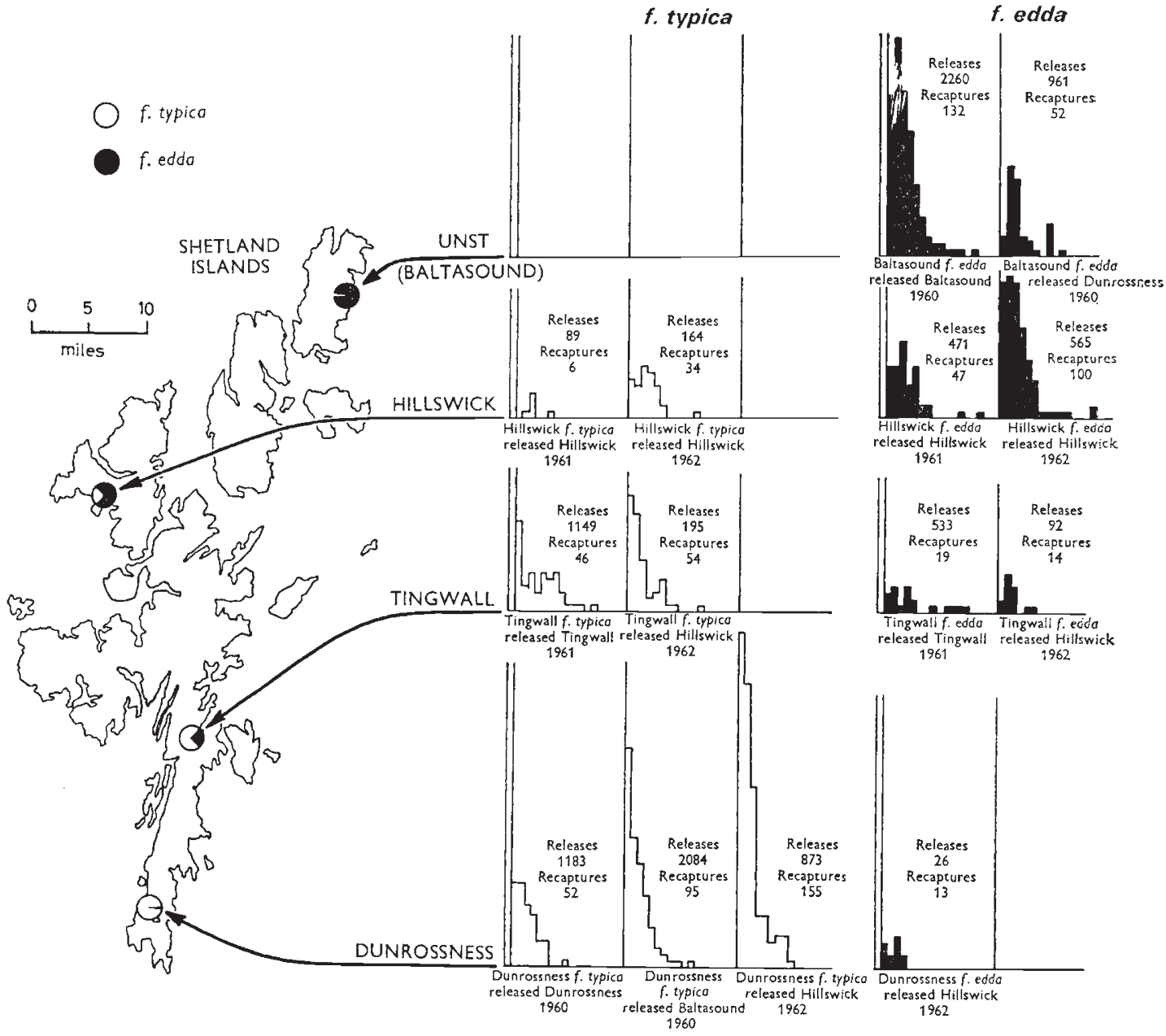

FIG. 1.-Map of Shetland showing the localities mentioned in the text, with histograms of moths recaptured on each day after release (data of table 1 ).

where the phenotype frequency decreased by 50 per cent. over a distance of about 15 miles. Mark-recapture experiments suggested that there were no significant differences in the survival of $f$. typica compared with $f$. edda at Dunrossness but that there was a $0.07 \pm 0.09$ advantage for $f$. edda at Baltasound where predation by birds was a common daily sight. However, there was a most unusual pattern in the time distribution of $f$. edda recaptures: instead of the highest number of recaptures being on the first day after release, as is normal in release-recapture experiments and was observed with $f$. typica recaptures in both Dunrossness and Baltasound experiments, there was a 
significant deficiency $(P>1$ per cent.) of moths on the first day. All our samples were taken at mercury vapour light traps with the entrances three feet above ground level. Each moth captured, therefore, was in flight. Kettlewell $(1961 b)$ concluded that the anomalous distribution reflected a diminished flight activity in $A$. glareosa of Unst origin. (Over 92 per cent. f. edda released were originally caught at Baltasound, and 90 per cent. of $f$. typica originated in Dunrossness).

In 1961 we carried out two separate mark-release-recapture experiments : one in the vicinity of the Tingwall Valley in the Central Mainland ( f.edda $=$ 26 per cent.: Kettlewell and Berry, 1968), and the other at Hillswick in the North Mainland ( $f . e d d a=76$ per cent.). In the same year Dr Peter Harper undertook a small mark-release-recapture experiment with $A$. glareosa at Braunton Burrows in Devon to test whether the peculiar pattern of recaptures we found in $f$. edda from Unst occurred in an English population of the species (where $f . e d d a$ has never been recorded). We are grateful to him for allowing us to quote his results. Finally, in 1962 we released at Hillswick A. glareosa from three different sources: Hillswick, Tingwall and Dunrossness, moths from each source being given a different mark so that their origin could be recognised if theywere recaptured. In all years we supplemented the main experiments with direct observations of behaviour. We also shot a number of birds seen feeding on insects in areas where $A$. glareosa was common, for analysis of their stomach contents.

\section{REsults}

\section{(i) Recaptures of marked moths}

The main object of the mark-release-recapture experiment, in 1961-2 was to determine the relative survivals of $f$. typica and $f$. edda in different localities, and to test if the anomalous behaviour pattern shown in $f$. edda recaptures from Unst in 1960 occurred elsewhere. Accordingly we have summarised our data as the recoveries of each form on each day after their original release (table 1 and fig. 1). The proportion of marked moths recaptured in each experiment is a reflection of the number of traps near the release ground, although differences at the same site between morphs and between moths of different origins are presumably valid. However a more useful index for comparison is the mean survival time in each experiment after release, since the length of survival of a moth must have a high correlation with its chance of reproducing and hence its biological "success".

An expected " normal " recapture pattern has been devised by summing the four experiments where the recaptures followed indubitably the usual exponential population decay curve (the three releases of Dunrossness-caught $f$. typica, and the release of $f$. typica Braunton Burrows), and the numbers of recaptures expected on this basis were calculated for the other eleven experiments (counting both sides of the Tingwall Valley together). This makes it possible to calculate a difference statistic for the fit between observed and expected distributions. Although this does not measure anything other than difference from the assumed "normal" distribution, the overall survival rates of $f$. edda and $f$. typica are sufficiently similar ( 3.5 and 3.0 days respectively) for the comparisons to be meaningful. Comparisons have been made for the first nine days of recaptures (this included 97.6 per cent. of all recaptures) and are expressed as $\chi_{8}^{2}$. In all the eleven experiments in 


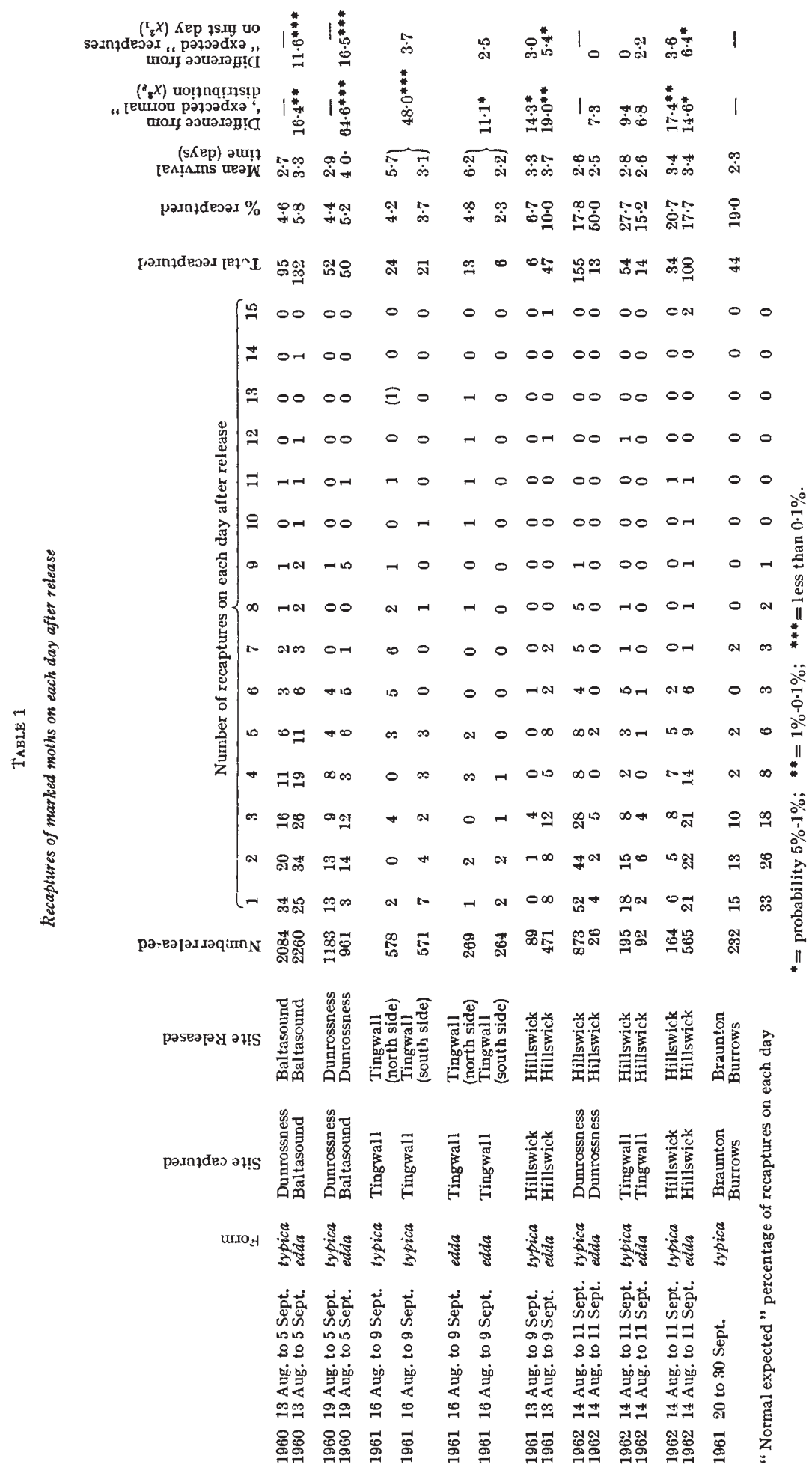


which there was not an unequivocal " normal" recapture pattern, there were fewer moths captured than expected on the first day after release. This deficiency of first day recaptures is expressed in table 1 as $\chi_{1}^{2}$. Kettlewell (1961b) described a method of assessing the recapture data using a technique devised by G. A. B. Smith for sibship studies in duodenal ulcer (Clarke, Edwards, Haddock, Howes-Evans, McConnell and Sheppard, 1956). The computations and comprehendibility of this method are more difficult than the one described above, and therefore we have not used it in our present analyses.

\section{(ii) Variation within $\mathrm{f}$. edda}

There is no difficulty in distinguishing $f$. edda from $f$. typica except in extremely worn specimens. A small number of $A$. glareosa (about one in 2000) cannot be referred to either $f$. typica or $f$. edda and probably represent

\section{TABLe 2}

Numbers of light and dark $\mathrm{f}$. edda in wild-caught samples

\begin{tabular}{|c|c|c|c|c|c|c|c|c|c|}
\hline & \multirow[b]{3}{*}{$\begin{array}{l}\% \text { frequency } \\
\text { of } f . \text { typica }\end{array}$} & \multirow{2}{*}{\multicolumn{4}{|c|}{ Numbers of }} & \multicolumn{4}{|c|}{$\begin{array}{l}\text { Observed }^{1} \text { and expected } \\
\text { percentage frequencies of }\end{array}$} \\
\hline & & & & & & $e d d a$ he & rozygotes & edda ho & lozygotes \\
\hline & & $\begin{array}{l}\text { light } \\
\text { f. edda }\end{array}$ & $\begin{array}{c}\text { dark } \\
f . e d d a\end{array}$ & $\underset{\text { typica }}{f .}$ & total & observed & expected & observed & expected \\
\hline Baltasound & $3 \cdot 0$ & 300 & 2162 & 77 & 2539 & $11 \cdot 8$ & $28 \cdot 8$ & $85 \cdot 2$ & $68 \cdot 2$ \\
\hline Hillswick & $23 \cdot 6$ & 602 & 355 & 295 & 1252 & $48 \cdot 1$ & $50 \cdot 0$ & $28 \cdot 3$ & $26 \cdot 5$ \\
\hline Tingwall & $73 \cdot 6$ & 287 & 33 & 893 & 1213 & $23 \cdot 7$ & $24 \cdot 4$ & $2 \cdot 7$ & $2 \cdot 0$ \\
\hline Dunrossness & $97 \cdot 5$ & 19 & 5 & 933 & 957 & $2 \cdot 0$ & $2 \cdot 5$ & 0.5 & 0 \\
\hline
\end{tabular}

another genotype (Kettlewell and Berry, 1961). However, there is considerable variation in the intensity of pigmentation of $f$. edda, and although there is no clear distinction between light and $\operatorname{dark} f$. $e d d a$, the great majority of melanics can be classified consistently as one class or the other. Kettlewell (1961 a) suggested from breeding data that the light moths were heterozygous for the edda allelomorph, and we have classified many of our samples into light and $\operatorname{dark} f$. edda (table 2).

\section{(iii) Bird stomach contents}

In 1960 we shot three common gulls (Larus canus L.) near Baltasound which we had observed feeding on insects in an area where $A$. glareosa was common. Three out of 18 identifiable $A$. glareosa in their stomachs were f. typica. In 1962 we shot two common gulls and six hooded crows (Corvus cormix L.) in the same place. A. glareosa was found in the stomachs of both species, and three out of eleven were $f$. typica. The overall frequency of $f$. typica in the stomach contents was therefore 11 per cent. in an area where the frequency of the morph was 3 per cent. 


\section{Discussion}

There is strong visual selection in favour of $f$. edda on Unst, the northernmost of the Shetland islands (Kettlewell, 1961b, and see above). In the extreme south of the islands is an extensive area of sand-dunes where migrating birds congregate while they await favourable winds and where a priorif. typica would be expected to be more cryptic than f. edda (Kettlewell, 1963). In all the intervening region (comprising the major part of Shetland) we have observed little sign of bird predation, although the evidence from the stability of phenotype frequencies from place to place and year to year show that strong selective forces must be acting throughout to maintain the observed $f$. edda frequencies (Kettlewell and Berry, 1968). We have argued that this selection must be "concerned with behavioural and physiological requirements for maintaining the integrity of co-adapted gene complexes". The evidence presented in this paper must be considered against this background.

\section{(i) Local adaptation}

The results from the recapture of marked moths are consistent and coherent both in terms of the mean survival time of recaptured moths in different experiments, and the unusual flight habit shown by some samples.

\section{(a) Survival in the local population}

Both $f$. typica and $f$. edda released at their sites of origin have a longer survival time than moths introduced from elsewhere. Thus $f$. typica and f. edda of local origin at Hillswick in 1962 survived 3.4 days (approximately the same as in 196I), whereas the morphs from Dunrossness which were released with them only survived 2.6 and 2.5 days respectively and the Tingwall morphs, $2 \cdot 8$ and $2 \cdot 6$ days respectively. The differences in survival time of the Dunrossness morphs relative to Hillswick were significant at the 5 per cent. level $(d=2 \cdot 15$ for $f$. typica and 2.02 for $f$. edda).

\section{(b) Reduced survival time in areas other than the one of origin}

With one exception, moths released at a site other than their site of origin have a reduced survival time. The differences are small but consistent. Thus the mean survival of marked $f$. typica at Dunrossness in 1960 was 2.9 days, but Dunrossness $f$. typica released at Baltasound in 1960 was 2.7 days and 2.6 days at Hillswick in 1962. Tingwall $f$. typica survived 4.7 days on average when released at Tingwall in 196I, but only $2 \cdot 8$ days when released at Tingwall in 1962; while Tingwall $f$. edda survived 5.0 days at Tingwall, $2 \cdot 6$ days at Hillswick. The survival time of the Tingwall morphs released at Hillswick are both significantly reduced at the 1 per cent. probability level $(d=3.57$ for $f$. typica and 2.54 for $f$. edda $)$. The exception to the rule of " best survival at home" was $f$. edda from Baltasound, which lived longer when released at Dunrossness ( 4.0 days) than at its home site ( 3.3 days) $(d=1 \cdot 88$; probability of this difference occurring by chance approximately 6 per cent.). The possible meaning of this exception is discussed below, but at least it answers the possible criticism that the mere fact of transport placed the moths at a disadvantage. 
(c) Relative survival of $\mathrm{f}$. typica and $\mathrm{f}$. edda

$F$. edda never had a lower survival than $f$. typica when both morphs were released together at their site of origin (Tingwall, 1961; Hillswick, 1961, 1962), but $f$. typica has a higher survival than $f$. edda from the same place when both morphs were released elsewhere (Dunrossness and Tingwall moths released at Hillswick in 1962). However, both morphs of the same origin when released together had approximately the same survival times whether they were released at their site of origin or elsewhere. This is true for moths captured and released at Tingwall and at Hillswick in 1961, and for moths caught at Dunrossness, Tingwall and Hillswick, and released at Hillswick in 1962. Unfortunately the one place where we know bird predation was occurring during the release-recapture experiments (Baltasound) had such a low frequency of $f$. typica in the population that we were never able to collect enough individuals of that morph to carry out an experiment.

Thus all the evidence points to the conclusions that $f$. typica and $f$. edda from different sites are not homogeneous, and that there is a considerable degree of local adaptation which is more important for $f$. edda than $f$. typica. The increased survival of Baltasound $f$. edda moved to Dunrossness (unless it is purely fortuitous) may be regarded as the cosequence of lower predation pressure or of the introduction of a favourable phenotype which is normally maintained at a low frequency because of the organisation of the local genecomplex.

The genetical heterogeneity of $A$. glareosa in Shetland is further shown by two completely different pieces of evidence:

\section{(ii) Flight habit differences}

One of us (Kettlewell 1961b) has shown previously that Baltasound f. edda had an atypical recapture pattern in that fewer moths were recaptured on the first night after release than on the second. This " first night deficiency" was entirely unexpected and has never been found in any releaserecapture experiment in any other species. The small experiment with Amathes glareosa in Devon by Harper (see Results) showed an entirely normal recapture pattern. Kettlewell $(1961 b)$ argued from both the recapture figures and direct observations of the time of flight of resting moths that Baltasound $f$. edda had a reduced flight activity when compared with Dunrossness $f$. typica. It is easy to devise a simple actuarial model to fit the observed pattern of Baltasound $f$. edda recaptures by postulating that only a proportion of the moths fly every night (fig. 2), and there are a number of comparable situations in which a physiological basis for such behaviour has been suggested (e.g. Kalmus, 1941). Reduced flight activity in a moth living on a windswept island would have adaptive significance, since only a proportion of the population would be subject to elimination on any particular night. It is a common finding that insects on islands are apterous (Darwin, 1855; Jeannel, 1925; Darlington, 1943).

However the original flight habit difference was not a difference between $f$. typica and $f$. edda as such (Kettlewell 1961b). Fig. 1 shows that the recapture patterns of moths depend on their origin, and not their morph or their place of release. For example, Dunrossness $f$. typica moths had a " normal" recapture pattern whether they were released at Dunrossness, Hillswick or Baltasound, whereas Baltasound $f$. edda showed a reduced flight habit 
when released either at Baltasound or at Dunrossness. However $f$. typica and $f$. edda from Hillswick had recapture patterns significantly different from "normal" in both 1961 and 1962, although only $f$. edda had a significant deficiency of first day recaptures. The recaptures of both Tingwall morphs differed from " normal" when released at Tingwall in 1961,

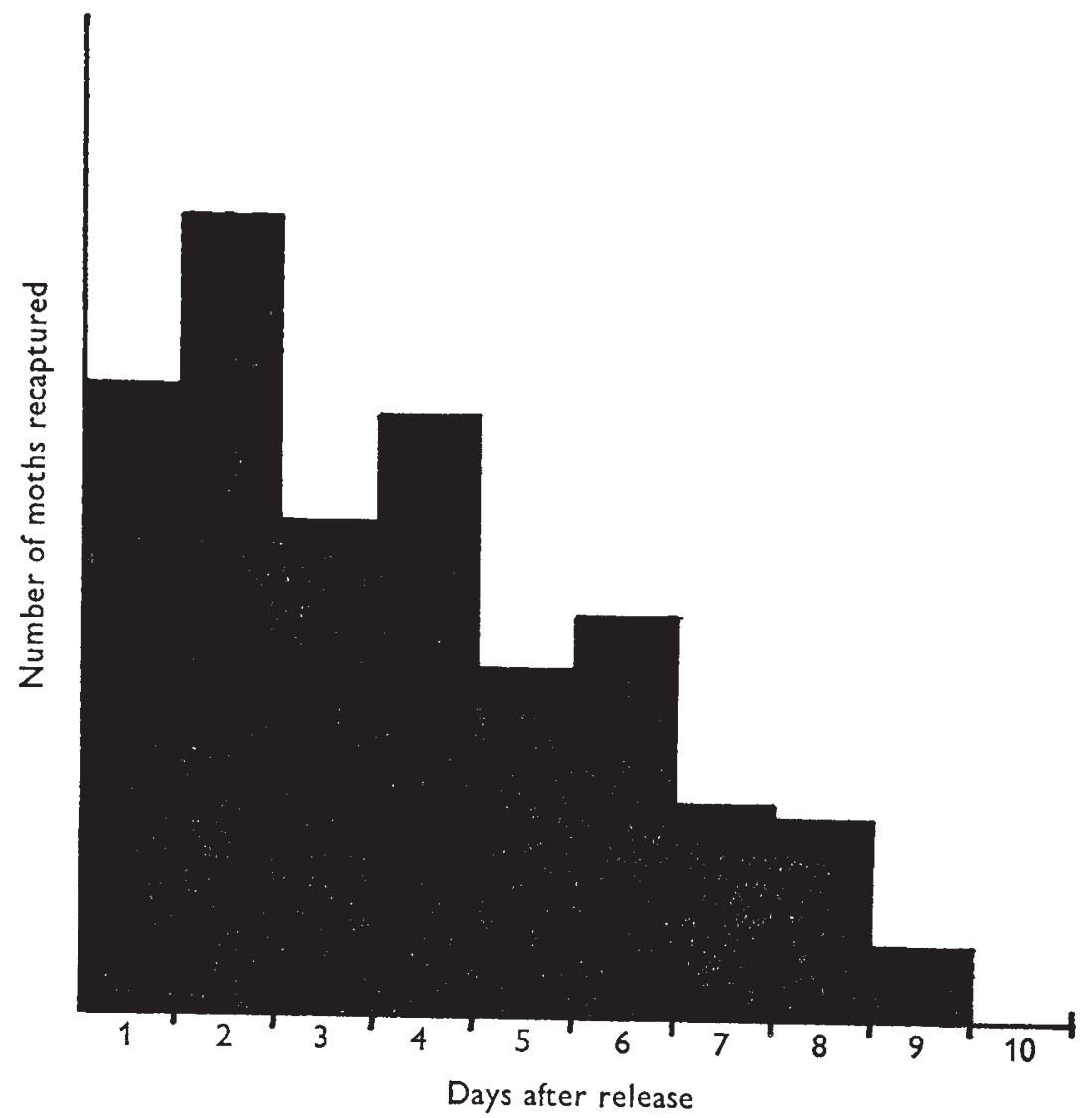

FIG. 2.- Histogram of the expected pattern of recaptures if 70 per cent. of moths fly every night, 30 per cent. every other night, and the death rate is constant throughout life whether flight takes place or not.

but both fitted the " normal" pattern when released at Hillswick in 1962. In no case was there a significant first day deficiency of either Tingwall morph. The small sample of Dunrossness $f$. edda released at Hillswick in 1962 did not differ from " normal ".

The conclusion must be, therefore, that it is the northern Shetland population of $A$. glareosa, irrespective of whether it is the typical of the melanic form, which has the anomalous recapture pattern. The Tingwall samples do not fall clearly into either the northern or southern behavioural population. Possibly there is a continual change in behavioural characteristics over the Shetland population, but it is relevant to note that Kettlewell and Berry (1968) concluded from a consideration of changes in $f$. edda frequencies over a limited area, that the Tingwall Valley lies near the border of two coadapted 
populations. Unfortunately both experiments in which $f$. edda recaptures did not differ significantly from "normal" were based on very small numbers so the question of whether $f$. edda ever has a " normal " recapture pattern must be regarded as undecided.

\section{(iii) Dominance differences}

The final way in which our data show genetical heterogeneity is in the extent to which the heterozygotes for the edda gene can be scored. At Dunrossness, Tingwall and Hillswick there are no significant differences between the observed number of light $f$. edda and the expected number of $e d d a$ heterozygotes on the assumption that the Hardy-Weinberg equilibrium is operating (table 2). However, at Baltasound less than half of the expected number of heterozygotes were recognised. This is too big a discrepancy to be due to observer error. It could be due either to differential elimination or to mis-classification of heterozygotes. It is impossible to exclude either of these, but since the Mainland samples show no sign of reduced viability of the heterozygote and since dominance might be expected to become more complete in a population containing a high proportion of homozygotes for the allelomorph (Fisher, 1928; Haldane, 1956; Clarke and Sheppard, 1960), we are inclined to accept that it represents a real difference in dominance modification between the Unst and Mainland populations.

\section{Conclusion}

When we began our work on Amathes glareosa in 1959, f. edda had not been reported to occur outside Unst (other than on Fair Isle, Williamson, 1956). It soon became clear that there was a cline in $f$. edda frequencies throughout the length of Shetland, and it appeared that if we could discover the reasons for the changes in frequency, we should understand the factors responsible for the maintenance of the melanic form. This was probably too sanguine. The results presented in this paper show that there are three progressive genetical changes (i.e. clines) in $A$. glareosa in Shetland apart from the visually obvious one of melanism. These are:

1. A degree of local adaptation of both $f$. typica and $f$. edda in all the populations sampled, presumably involving complex genetical adjustments to all the different situations in which $A$. glareosa lives.

2. A behavioural difference between the northern and southern Shetland populations (both $f$. edda and $f$. typica), representing a decreased flight activity of the northern moths. The Tingwall valley seems to represent an intermediate area in this cline.

3. A greater degree of dominance modification in the Unst population than in the Mainland population.

These three situations were all detected incidentally. Two of them were revealed through the use of mark-release-recapture techniques, and, as recorded earlier (Kettlewell, 1961b), this is the first time that a habit difference has been demonstrated in a polymorphic insect in the wild by such methods.

The genetical complexity of $A$. glareosa in Shetland is a salutary reminder of the facile dangers of over-simplified explanations of natural systems. Although the classical elements of Lepidopteran melanism as found in 
industrial areas were all present, viz. a dominantly-inherited melanic form, a high degree of crypsis and intensive bird predation (Kettlewell, 1956), nevertheless, $A$. glareosa in Shetland has a much more subtle relationship with its environments than is at first apparent. It is becoming increasingly clear that the situation in industrial melanics, particularly those which have reached equilibrium, may be equally complex (Kettlewell, 1965; Clarke and Sheppard, 1966). We believe that we have succeeded in our original aim, and that the understanding that we have gained about the genetical structure of the non-industrial $f$. edda melanic population will be of relevance for our understanding of the early spread of industrial melanics.

\section{Summary}

1. The frequency of the melanic $f . e d d a$ of the noctuid (caradrinid) moth Amathes glareosa decreases from 97 per cent. in the north of the Shetland islands to less than 1 per cent. in the south.

2. Mark-release-recapture studies have shown that populations in different parts of the islands have undergone a degree of local adaptation, in that the survivals of marked $f$. edda and $f$. typica were consistently higher when they were released near to the site at which they were caught than when they were released elsewhere.

3. Both morphs of the species have a decreased flight activity in north Shetland. This results in a reduced number of captures of moths on the first day after release. Moths from south Shetland have a more normal pattern of recaptures. The population from the middle of the main island showed an intermediate behaviour.

4. Only half the expected number of $e d d a$ heterozygotes could be scored in the northernmost island of Unst, although the expected numbers of heterozygotes were recognised as light $f$. edda elsewhere. This probably represents an increased degree of dominance of the edda phenotype in the Unst sample.

5. Thus there are clines in the allelomorph determining the $f$. edda phenotype, in local adaptation, in behavioural characteristics, and in dominance modification.

6 . Few genetically varying populations have been studied as intensively as that of Amathes glareosa in Shetland. There is no reason for believing that the genetical population structure we have shown is unusual. We suggest that the genetical heterogeneity which we have found in $A$. glareosa will be a useful model for the study of other polymorphic systems.

Acknowledgments.-The study reported in this paper was carried out with the help of numerous co-workers in the field, and with the co-operation of many Shetlanders, to all of whom we record our thanks. We are grateful also to Professor E. B. Ford, F.R.S., Dr E. R. Creed and Mr David Lees for their comments on the manuscript, to Professors C. A. B. Smith and H. Kalmus for assistance with particular points, and to Mr A. J. Lee for drawing the figures.

We were enabled to do this work because of the generous financial help of the Department of Scientific and Industrial Research (H.B.D.K. and C.J.C.), the Medical Research Council (R.J.B.), and the Nature Conservancy (G.C.P.).

\section{REFERENGES}

CLARKE, C. A., EDWARDS, J., HADDOCK, D. R. W., HOWES-EVANS, A. W., MCCONNELL, R. B., AND SHEPPARD, P. M. 1956. ABO Blood groups and secretor character in duodenal ulcer. Brit. med. J., ii, 725. 
CLARKE, C. A., AND SHEPPARD, P. M. 1960. The evolution of dominance under disruptive selection. Heredity, 14, 73-87.

CLARKE, C. A., AND SHEPPARD, P. M. 1966. A local survey of the distribution of industrial melanic forms in the moth Biston betularia and estimates of the selective values of these in an industrial environment. Proc. roy. Soc. B., 165, 424-439.

DARLINGTON, P. J. 1943. Carabidae of mountains and islands: data on the evolution of isolated faunas, and on atrophy of wings. Ecol. Mongr., 13, 37-61.

DARwin, C. R. 1855. Letter to J. D. Hooker, 7th March 1855, in Darwin, F. (ed.) (1887). Life and Letters of Charles Darwin. London, Murray.

FISHER, R. A. 1928. The possible modification of the response of the wild type to recurrent mutations. Amer. Nat., 62, 115-126.

HALDANE, J. B.s. 1956. The theory of selection for melanism in Lepidoptera. Proc. roy. Soc. B., $145,303-306$.

JEAnnel, R. 1925. L'apterisme chez les insectes insulaires. C. R. Acad. Sci., Paris, 180 $1222-1224$.

KALMUS, H. 1941. Egg-laying of ducks as an enforced relaxation oscillation. Nature, Lond., $148,626-627$.

KETTLEWELL, H. B. D. 1956. A resume of investigations on the evolution of melanism in the Lepidoptera. Proc. roy. Soc. B., 145, 297-303.

KetTleWELL, H. B. D. 1957. Industrial melanism in moths and its contribution to our knowledge of evolution. Proc. roy. Instn., 36, 1-13.

KetTLEWELl, H. B. D. $1961 a$. Geographical melanism in the Lepidoptera of Shetland. Heredity, 16, 393-402.

kettlewell, H. B. D. 1961 b. Selection experiments on melanism in Amathes glareosa Esp. Heredity, 16, 415-434.

KETTLEWELL, H. B. D. 1963. Recent advances in our knowledge of melanism in the Lepidoptera. Proc. XVI Int. Congr. Zool., Wash., 2, 197-198.

KETTLEWELL, H.B.D. 1965. Insect survival and selection for pattern. Science, 148, 1290-1296. KETTLEWELl, H. B. D., AND BERRY, R.J. 1961. The study of a cline. Amathes glareosa Esp. and its melanic $f$. edda Staud. (Lep.) in Shetland. Heredity, 16, 403-414.

kettlewell, H. B. D., AND BerRy, R. J. 1969. Gene flow in a cline. Amathes glareosa Esp. and its melanic $f$. edda Staud. (Lep.) in Shetland. Heredity, 24, 1-14.

williamson, K. 1956. Birds and lepidoptera in anticyclonic airstreams. Ent. Rec., 68, 95-97. 